\title{
Sovyet Düşüncesinin Aydınlık Mecmuası (1921) Üzerindeki Etkisi ve Faruk Nafiz'in Sanat Şiirinin Bir Öncülü
}

\author{
Dinçer APAYDIN ${ }^{1}$
}

\begin{abstract}
$\ddot{\mathbf{O} z}$
Cumhuriyet'in ilanından önce millîleşme ve dünyevileşme hamlelerinin etkisiyle gelişimini sürdüren Türk şiirinin, özellikle Nâzım Hikmet ve onu takip eden şairler tarafindan Sovyet ekolünden gelen sanat anlayışıyla tanıştırıldığı bilinmektedir. On dokuzuncu yüzyllın başlarından itibaren batı medeniyeti -özellikle Fransa- ile kültürel ilişkiler kuran Türk edebiyatının, Sovyet coğrafyasından gelen bu etkiden edindiği kazanımlar Türk şiirinin doğal seyri içinde önemli bazı değişikliklerin yaşanmasına olanak sağlar. Serbest nazım ve şiirde biçimsel birtakım tasarrufların öncü şairi olan Nâzım Hikmet, bu ilişki içindeki rolü ve kendisine has söyleyişiyle modern Türk şiiri için çok iyi tanınan bir figürdür. Bununla birlikte şairin de etkin olarak yer aldığı Aydınlık mecmuasında biçim, üslup ve söyleyiş açısından Nâzım Hikmet'in tarzını takip ederken ideolojik bağlamda Sovyetler'le ilişki kuran bazı başka şairlerin varlı̆̆ı yeterince bilinmemektedir. Ayrıca, adı geçen dergide Faruk Nafiz gibi Türk şiirinde farklı bir söylemin içinde yer etmiş, tanınan bir şairin de dönemin etkisinde yazıldığı sezilen bir şiirine rastlanmaktadır. Bu çalışmada Aydınlık mecmuasında Sovyet ideolojisi ile ilişki kuran ve ikinci planda kalmış şair ile şiirlerden söz edilecek; Faruk Nafiz’in memleketçi edebiyat anlayışının poetikası mahiyetinde olan Sanat adlı şiirinin öncülü olduğu düşünülen Anadolu’ya adlı şiiri çözümlenecektir.
\end{abstract}

Anahtar kelimeler: Cumhuriyet Dönemi Türk Şiiri, Aydınlık Mecmuası, Sekülarizm, Serbest Nazım, Faruk Nafiz Çamlıbel.

\section{The Influence of the Soviet Thought on the Aydrnlk Magazine (1921) A prototype of Faruk Nafiz's Poem Sanat}

\begin{abstract}
It is known that the Turkish poetry, which continued to develop with the influence of the movements of nationalization and secularization, was introduced to the understanding of art from the Soviet school by Nazım Hikmet and the poets following him. These influences from the Soviet geography of Turkish literature which has established cultural relations with western civilization since the beginning of the nineteenth century, especially France, allow for significant changes in the natural course of Turkish poetry. Nâzım Hikmet, who is the leading poet of free verse, is a well-known figure for modern Turkish poetry with his role in this relationship and his own remark. However, followers of Nâzım Hikmet in terms of form, style and utterance in the Aydınlık magazine where the poet actively took place, the presence of some other poets who related to the Soviets in the ideological context is not well known. Moreover, in the mentioned magazine Faruk Nafiz, a recognized poet who has been included in a different discourse in Turkish poetry, has also found with a poem written under the influence of the period. In this study, poetry that relate to the Soviet ideology and remain in the second plan will be mentioned in the Aydinlk magazine and a poem which is thought a prototype of Faruk Nafiz's milestone poem of the nationalist discourse Sanat will be analyzed.
\end{abstract}

Arş. Gör. Dr., Gazi Üniversitesi, Edebiyat Fakültesi, Türk Dili ve Edebiyatı Bölümü, dincerapaydin@gazi.edu.tr [Makale kaylt tarihi: 8.7.2018-kabul tarihi: 15.8.2018] 
Key words: Republican Period Turkish Poetry, Aydınlık (Literary Magazine), Secularism, Free Verse, Faruk Nafiz Çamlıbel.

Aydınlı mecmuası 1921 yılında yayın hayatına başlayan ve özellikle Erken Cumhuriyet Dönemi Türk Şïrinin şekillenmesinde etkili olan süreli yayınlardan biridir. Bu dergide yayımlanan metinlerden çoğunun Sovyet düşüncesini ve ideolojisini Anadolu coğrafyasına tanıtmak işlevi yüklendiği düşünülebilir. Sanatsal metinlerde ve özellikle şiirde, Nazım Hikmet’in serbest nazımla ilgili tasarrufları gözetilerek oluşturulan söyleyiş biçimleri de sözü edilen ideolojik tercihin etkisi altındadır.

Türkiye Cumhuriyeti’nin resmen kuruluşundan sonra inkılapların yaygınlaştırılması ve Anadolu halkının şiirde yer edinmesine öncelik vererek, millı̂ edebiyat anlayışından memleketçi bir edebiyat anlayışına evrilen hececi şiirin önemli temsilcilerinden Faruk Nafiz'in de 1920'li yılların ortalarında bu dergide bir şiir yayımladığı görülür. Şairin içinde bulunduğu söyleme ters düşen bir paradigmanın yayın organında metin yayımlaması göstergesel bir değer taşımaktadır. Şairin bu şiirini konumlandırabilmek için öncelikli olarak Aydınlık mecmuasında yayımlanmış, Sovyet düşüncesinden izler taşıyan şiirlerin bir kısmını incelemek ve derginin şiir söylemini anlaşılır kılmak yerinde olacaktır.

Aydınlık mecmuasında yayımlanan şiirler arasında Sovyetlerin düşünce dünyasıyla ilişki kurmak bağlamında öne çlkan şiirler, öncelikle Nâzım Hikmet'e aittir. Şairin kanon içindeki pozisyonunu belirleyen ve biçimsel yenilikleriyle göze çarpan şiirlerinin bütünlüklü bir şekilde yayımladığ ilk yer Aydınlık olmuştur. Yeni Sanat, Grev, Ustamızın Ölümü, Aydınlıçılar, Komsomol gibi şiirlerini Aydınlık'ta yayımlayan Nâzım Hikmet’in bütün şiirlerinin bir araya getirildiği kitapta Sağhlğında Yayımladığı Yeni Biçimli İlk Şiirleri başlığı altında geçen (Nâzım Hikmet, 2011) bu metinler, kendisinin meydana getirdiği akıma kapılarak gerek onun yenilikçi tarafını taklit etmek gerekse mecmuanın Sovyet düşünce dünyasıyla kurduğu ilişkiyi klasik söyleyişle birleştirerek ifade etmek suretiyle dergide beliren diğer şairlere hareket alanı açmıştır. Dolayısıyla özellikle Nâzım Hikmet’in dışındaki şairlerin metinlerine de bakmak, dergiye yerleşen ve tüm yazarları tarafından benimsenen ideolojik söylemin özelliklerini tespit edebilmek için önemlidir.

Örneğin Aydınlık'ta divan şiiri terbiyesiyle yetişmiş bir şair olan Yaşar Nezihe'nin 1923 yllında yayımlanan Kızıl Güller adlı şiiri, Türk şiirinin geleneksel mazmunlarından biri, belki de en güçlüsü, olan "gül” üzerinden kurulmuş bir imajla okuyucunun karşısına çıkmaktadır. Bu karşılaşma her ne kadar klasik şiir terbiyesinin getirdiği özelliklere bağl görünse de aslında bir o kadar yenilikçi ve karşı gelicidir:

\author{
KIZIL GÜLLER \\ Bu baharın da gülleri ne kadar \\ -Lekelenmiş şehit kanıyla gibi- \\ Ateşîndi, kızıldı yarabbi! \\ Güller oldu bu yıl da çeşmime hâr. \\ Sevmedim gülleri bu yıl da yine \\ Öyle gül isterim ki gülmelidir. \\ Bana 'kardeşlik' hissi vermelidir... \\ Koklamak güçtür hârı gül yerine.
}


The Influence of the Soviet Thought on the Aydinlk Magazine (1921) A prototype of Faruk Nafiz's Poem Sanat / D. Apaydin (p. 12-20)

Rüzgârlarla savrulup gele gele;

O kızıl güller hâke kalp oluyor...

Bir emel ki açılmadan soluyor.

Olmuyor koklamak nasip öyle!

Kırk bahar geçti de hayatımdan

Bir kızıl gül koparmadım hala...

Bir bahar gülleriyle gelse bana

Beklerim bunu hep sebatımdan...

Böyle alûde-i meşakk u muhan

Gelecek nevbahara muntazırım

Beklerim; beklemekle müftehirim:

'Beşerin kurtuluş' baharını ben.

Yaşar Nezihe (Aydınlık, S.16, 1 Haziran 1923, s.415)

Biçim ve kelime kadrosu olarak geleneksel olana bağlı görünen metnin gül mazmununu kullanış tarzı, Türk şiirinin geleneksel yapısıyla kurulan ilişkinin üzerinde yeniden düşünüldüğünün göstergesidir. Ancak bir içerik unsuru olarak metindeki "gül"ün nitelikleri okunduğunda "Beşerin kurtuluş baharını" bekleyen, "ömründe kırk bahar geçmesine rağmen bir kzzl gül koparamayan” özne, "öyle bir gül istemektedir ki bu gülün kendisine kardeşlik hissi vermesi” gerektiğini söylemektedir. Metnin girişinde bu bahar açılan güllerin kırmızılığını "şehit kanıyla lekelenmiş" benzetmesiyle sunan öznenin çağrıştırdığı değerler, henüz bağımsızlık savaşından çıkmış Türkiye'nin içinde bulunduğu durumu hatırlatmaktadır; ancak imajın kapsayıcılığı bununla sınırlandırılamaz. Çünkü:

1917 Ekim Devrimi ve bu devrimin mimarı Rusya Sosyal Demokrat İşçi Partisi’nin (Bolşevik) siyasî, kuramsal, ideolojik gücünün tüm dünyayı olduğu gibi Anadolu'yu da etkilemesinden daha doğal bir şey olamazdı. Dolayısıyla 1919-1920 yılları arasında Anadolu'da esen güçlü Bolșevizm rüzgârlarının doğrudan Bolşevik Partisi kaynaklı olduğuna ilişkin pek çok yorum bulunmaktadır (Akal, 2008:114).

Aydınlı mecmuasının sözü edilen zihniyete yakınlığı da göz önünde bulundurulduğunda "kırmızı" renginin Sosyalizm ve Bolşevik kültürüyle olan göstergesel ilişkisi; rengin arzuyu temsil etme özelliği ile birlikte düşünüldüğünde, metnin "kardeşlik" kavramı üzerinden "gül” mazmununu kırmızı renkli bir arzu nesnesi hâlinde vurguladığını da gösterir. "Kardeşlik" kavramı, gül mazmununun Türk şiirindeki tarihsel anlamını belirleyen "sevgili" kadar özlenmiş ve arzulanmıştır. Hatta daha doğru bir ifadeyle onun yerine kullanılmıştır.

Aynı dergide "Ahmet" imzasıyla yayımlanan bir başka şiir, toplumcu-gerçekçi şiirin özellikleri bağlamında, henüz adıyla dikkat çeken bir metindir:

\section{ŞARKA ÇEVIR YÜZÜNÜ}

Türkiye Emekçilerine

Yine böyle titredim, yine kaldım böyle lâl.

Bu ağlayan ses kimin, kim bu Avruparan hayal? 
Bakışları bulanık, yüzünün rengi ölü,

Yarı beline kadar bataklığa gömülü

Öyle bir bataklık ki: Susuz bir yığın çamur

Hangi kara bulutlu günden boşanan yağmur

Bu batağı yaratmış?

Sonra onun koynuna kim bu mahkûmu atmış?

Bu zavallı esirin burada bulduğu ne?

Yoksa hükmedilmiş mi açlıktan ölümüne?

Odun yığınlarının üstünde yatacak mı?

Yoksa taşlanacak mı? Yoksa taşlanacak mı?

İşte garp ufukları karardı baştanbaşa,

Mağripte bir siyah el onu tutuyor taşa...

Şimdi kör hücum ile dinmeyen bir yağmurun

Toprağı yumuşuyor saplandığı çamurun,

Etrafinda bataklık büyüyor, çoğalıyor,

Kurtulmak istedikçe daha fazla dalıyor,

Fakat hâlâ taş gelen tarafa dönmüş yüzü,

Hâlâ mağrip ufkunda dileniyor gündüzü...

Ah ey zavallı esir! Oradan ne bekliyorsun?

Bir güneş ver diyorsun?

Bir güneş ki yaratsın her şulesinde bir yaz.

Ebediyen kurutsun bu bataklığı, çukuru

Mademki senelerdir senin beklediğin bu;

Garba yalvarma artık, mağripten güneş doğmaz!

Eğer bir gün kurtulmak istiyorsan, mutlaka

Şarka çevir yüzünü, yüzünü çevir şarka!

Ahmet (Aydınlık, S.21, 1 Mayıs 1924 S.545)

Şiirin, "Türkiye Emekçilerine” ithafı ile başlıyor olması, "emek" sözcüğünün şiir alanında kendisine yer bulması bakımından ilgi çekicidir. Metnin 1 Mayıs 1924 yılında yayımlanmış olması ise İşçi Bayramı olarak bilinen 1 Mayıs Emek ve Dayanışma Günü’nün metnin yayımlanacağı tarih açısından gözetildiğini haber vermektedir. Şair öznenin bir bataklığın içinde "yarı beline kadar gömülü” olarak tasvir ettiği esir, Türkiye'dir. Ülkenin içinde bulunduğu bataklık toprağının giderek yumuşaması, Batı'daki siyah eller tarafından taşlanması; buna rağmen bu esirin hâlâ yüzünü taşın geldiği tarafa dönmesi ve oradan "güneş" beklemesi şeklinde somutlaştııılan imajda, batı uygarlığının tehlikeli tarafına işaret edilir. "Batıdan güneş doğmayacağı” ve güneşi görmek istiyorsa yüzünü şarka çevirmesi gerektiği özneye hatırlatılmaktadır. Tanzimat Fermanı’ndan bu yana Batı, özellikle Fransız kültürü ile 
The Influence of the Soviet Thought on the Aydmlık Magazine (1921) A prototype of Faruk Nafiz's Poem Sanat / D. Apaydın (p. 12-20)

ilişki içinde olmayı bir nevî devlet politikası hâline getirmiş bir toplumda, şiir üzerinden böylesi bir önerinin ileri sürülmüş olması toplumcu-gerçekçi şiirin fikre dayalı sanat anlayışını göstermesi bakımından önemlidir. "Doğu” sözcüğü ile işaret edilen tarafın, Bolşevik Devrimi sonrası Rusya olduğu açıktır. Dolayısıyla vurgulanan değerler manevî olanlardan çok, emek ve üretim ilişkisine dayanan maddî değerlerdir.

Sözü edilen devrimin, Bolşevik partisinin lideri ve en belirgin figürü olarak tarihe geçen ismi Vladimir Lenin, Aydınlık dergisince de benimsenmiş bir önder olarak öne çıkarılır. 1924 yılının Ağustos ayında dergide yayımlanan Genç Leninistler Türküsü adlı şiir, dergiyi çıkaranlarca Bolşevik zihniyetinin ne denli benimsendiğinin bir göstergesidir. Bir marş güftesi olarak da kabul edilebilecek metin, "Şarka Çevir Yüzünü" adlı yukarıdaki şiire adeta bir gönderme olarak okunabilecek şekilde, "Şarklı" mahlası ile kaleme alınmıştır:

\section{GENÇ LENINISTLER TÜRKÜSÜ}

'Senin yollarında yürüyoruz ve damarlarımızda senin kudretini hissediyoruz'

Biz bir kıvılcımız ki bir dünya yakarı!

Biz bir dünya mahvedip, bir dünya yaparız.

Mefkûrenin, ümidin,

Heyecanın, neşenin,

Kaynağıdır binimiz;

Alev gibi yanarız...

Ne alevden bunalır ne bu nura kanarız..

Bize tufan diyorlar!

Biz ne ateş ne kanız:

Her adımı bir hesap

Her bir sözü bir fikir,

Her birimiz bir âlem olan birer insanız.

Şarklı (Aydınlık, S.24, 1 Ağustos 1924, s.632)

Sürdürülen hayata dikkatini çevirmiş dünyevî zihniyetin şiirde "Biz ne ateş ne kanız; / Her adımı bir hesap / Her sözü bir fikir / Her birimiz bir âlem olan birer insanız” mısralarılyla belirginleştirdiği ilk unsur, imajın kuruluş biçiminde içsel özelliklerin ötelenmesi ve yerine dünyevî, insan aklı ve emeğine dayalı kavramların kullanılmış olmasıdır. Kıvılcım ve alev göstergeleriyle karşılanan yakıcı ve yeniden kurucu olan güç, hesap ve fikirdir.

Yayımlanan şiirlerden verilen örnekler göz önünde bulundurulduğunda Aydınlık Mecmuası'nın söylemini kuran temel öğelerden birincisinin Sovyet ideolojisinden gelen Sosyalist değerler olduğu görülür. Özellikle kırmızı renk ve ateş / güneş nesneleri etrafında kurulan imajlar hem soyut hem de somut göstergelerle şiir dilinde kendilerine yer bulur. Bu kızıllı̆̆ı dönemin belirleyici şairlerinden, saf şiirin temsilcisi Ahmet Hâşim’in doğadan izleyerek kurduğu kızıllık / günbatımı imajlarıyla ilişkisi olmadığı açıktır. Vurgulanan, Sovyet rejiminin bayrağı, ordusu, ideolojisiyle somutlaştırarak benimsediği ve ideolojinin bir temsiline dönüşen kırmızı rengidir. 
Aydınlık mecmuasının şiirdeki söylem özelliklerini belirleyen bu şartlar altında, Şairler Derneğı̈nden itibaren millî duyarlılığa yakın olduğu bilinen / düşünülen Faruk Nafiz [Çamlıbel], bu dergide Anadolu'ya adlı bir şiir yayımlar. Bu çalışmanın hareket noktasını oluşturan metin, aşă̆ıda verilen, sade söyleyişli iki dörtlükten ibarettir:

\author{
ANADOLU'YA \\ Ufkun güneş edalı serserisi \\ -Gördüm seni- söndü gözlerimde, \\ Yârim gibi şiirimin perisi \\ Bir kaltağa döndü gözlerimde. \\ Sardıkça saran hakikatinden \\ İçtim, susadım. Yedim, acıktım. \\ Zulmet gibi girdiğim çatından \\ Kıpkırmızı bir yürekle çıktım!
}

Faruk Nafiz (Aydınlık, S.26, 1 Ekim 1924, s.671)

Metnin Aydınlık mecmuasında yayımlanmış olması onun toplumcu bir hassasiyet taşıdığına dair bir izlenim oluşturur. Ancak şiirin temelinde, memleketçi ideolojinin de izleri vardır. Şair özne, ufkun güneş edalı serserisi olarak tanımladığı Anadolu'yu gördüğü andan itibaren, sanat için sanat anlayışını temsil eden şïr perisi imajının, kendi zihninde bir kaltağa dönüştüğünü ifade etmektedir. Bu sert söylem, dergideki toplumcu-gerçekçi havadan nasibini almış görünmektedir. Şiirdeki duygu hâlini kuran mısra ikinci dörtlüğün başındaki Sardıkça saran hakikatinden ifadesidir. Bu ifadeyle, gerçekçi bir edebiyat vücuda getirmenin bir tercih olmaktan ziyade yemek yemek ya da su içmek gibi bir ihtiyaç olduğunu işaret eden özne, Anadolu'nun çatısından kıpkırmızı bir yürekle çıktığını ifade etmektedir. Kırmızı renk ve onunla göstergeselleşen çeşitli nesneler, daha önce de ifade edildiği gibi, 1920'lerin başında toplumcu-gerçekçi şiirin kullandığı argümanın içinde sıklıkla rastlanan unsurlardır. Bu bağlamda, Faruk Nafiz'in de Aydınlık mecmuası edebî çevresinden en azından kelime kadrosu ve söyleyiş özellikleri açısından etkilenmiş olabileceği düşünülebilir. Metnin ideolojik yanı memleketçidir; ancak Anadolu'da yaşayan insanı esas alması bakımından toplumcu-gerçekçilik ile ortak bir hisse kapıldığı da söylenebilir. Bu durum, Faruk Nafiz’in memleketçi söylemini olgunlaştırmaya çalışırken toplumcugerçekçi duyuş tarzından da etkilenmiş olabileceğini göstermektedir. Bununla birlikte, yaygın olarak bilindiği üzere, şairin şiir geçmişine dair verilen hemen hemen tüm bilgilerde sıralanan ortak noktaların en önemlisi onun herhangi bir yabancı ideolojiden etkilenmemiş olduğu, millî duyarlılığa daima bağlı kaldığıdır:

[Faruk Nafiz] şiire aşk şiirleriyle başlamıştır. Bunlarda başlangıçta biraz Servetifünun havası görülse de onlarınkinden daha yeni, daha realist ve insanîdir. [...] İstiklal Savaşı sırasında Kayseri'de edebiyat hocalığı yapan şair, bize Anadolu’yu ve Anadolu insanını vermiş̧tir. Bu sıralarda ve biraz daha sonra Faruk Nafiz sosyal konulara da eğilir. Eşraf-Köylü mücadelesi, aç ve muztarip insanlar onu ilgilendirir. Fakat şair, bu konuları ele alırken bir sosyalist gibi hareket etmez. Esasen o, hiçbir zaman yabancı ve zararlı ideolojilere iltifat etmemiştir (Timurtaş, 1974: 192).

Bir şairin yaşadığı bütün dönemler boyunca aynı söylemin içinde kalmasının her zaman olası olamayacağı düşünüldüğünde, Faruk Nafiz'in de zaman içinde farklı ideolojik bağlamlardan etkilenebilmiş olacağı kabul edilebilir. Bununla birlikte Faruk Nafiz’in, memleketçi edebiyat anlayışının 
The Influence of the Soviet Thought on the Aydinlk Magazine (1921) A prototype of Faruk Nafiz's Poem Sanat / D. Apaydin (p. 12-20)

hâkim olduğu dönemlerde dahi Anadolu halkını konu edindiği şiirlerinde kimi zaman tuhaf olarak nitelendirilebilecek söyleyiş özellikleri gösterdiğini ifade edilen bir çalışmada, şairin Millî Mücadele yıllarındaki bir anısına da değinilmiştir:

İstanbul ve İzmir'in işgali üzerine 1919'da yazdığı manzumeler dışında, 1921 yllı başlarında yayımladığı "At" şiirine kadar iğreti bir ad yahut gizli bir imzayla da olsa Anadolu hareketini destekleyen herhangi bir şiirine rastlamadığımız Faruk Nafiz, söz konusu şiirinin yayımlanmasından hemen önce, arkadaşları Yusuf Ziya, Vâlâ Nureddin ve Nâzım Hikmet'le beraber Anadolu'ya geçmek istemiş, ancak "seciyesiz" olduğu gerekçesiyle İnebolu’dan geri çevrilmiştir (Sağlam, 2006: 73).

Vâlâ Nureddin ve Nâzım Hikmet gibi Sosyalist tandanslı şairlerin Millî Mücadele'ye katılma istekleri kabul görürken kendileriyle birlikte hareket eden ve millî - memleketçi edebiyat söylemine daha yakın olduğu düşünülen Faruk Nafiz’in kabul edilmeyişi, şairi netameli bir konuma yerleştirmektedir. Cumhuriyetin kuruluşundan sonraki siyasî hayatı da çeşitli çalkantılar ve kırgınlıklarla süregiden Faruk Nafiz'in en sonunda 1960'lı yıllarda Yassıada'da savunma yapmaya varacak süreci (Karakılıç, 2018) hem sürdürülen hayattaki ideolojik bağlamın hem de bir şairin içinde bulunduğu ideolojik söylemin zamanın ruhuna ve toplumsal kabullere göre nasıl değiştiğinin bir göstergesidir. Dolayısıyla Faruk Nafiz’in özellikle 1920'li yılların ilk yarısında gelişmekte olan şiir anlayışı, Sosyalizmin Türk edebiyatındaki kültürel izdüşümlerinden biri olan Toplumcu-gerçekçi şiirden de etkilenmiş olabilir. Elbette tek bir şiirle şairin düşünce dünyası hakkında kesin bir yargıya varılamaz; fakat sözü edilen bu tek şiirin bulunduğu mecra ve söylemindeki göstergeler, ileri sürülen bu varsayımı destekler ve düşünülür kılar niteliktedir.

Nitekim Aydınlı mecmuasında rastlanan Anadolu'ya adlı metnin hem ses ve söyleyiş hem de ideoloji bakımından olgunlaşmış hâli, iki yl sonra Türkiye Cumhuriyeti'nin temel değerlerini, Türkiye Cumhuriyeti'nin başkentinden edebiyata aktarmakta öne çıkan Hayat mecmuasında yayımlanır. Memleketçi şiirin adeta poetikası sayılabilecek Sanat adlı şiir (Çıkla, 2010: 275-276), sanat yapmak gayesiyle hareket eden şiir anlayışı başta olmak üzere diğer şiir anlayışlarından da yolunu kesin çizgilerle ayırır:

\section{SANAT}

Yalnız senin gezdiğin bahçede açmaz çiçek,

Bizim diyarımızda bin bir baharı saklar!

Kolumuzdan tutarak sen istersen bizi çek

İncinir düz caddede dağda gezen ayaklar

Sen kubbesinde ince bir mozaik arar da

Gezersin kırk asırlık mabedin içini

Bizi sarsar bir sülüs yazı görsek duvarda,

Bize heyecan verir bir parça yeşil çini

Sen raksına dalarken için titrer derinden

Çiçekli bir sahnede bir beyaz kelebeğin

Bizimde kalbimizi kımıldatır derinden

Toprağa diz vuruşu dağ gibi bir zeybeğin

Fırtınayı andıran orkestra sesleri 
Bir ürperiş getirir senin sinirlerine,

Istırap çekenlerin acıklı nefesleri

Bizde geçer en yanık bir musiki yerine

Sen anlayan bir gözle süzersin uzun uzun

Yabancı bir şehirde bir kadın heykelini,

Biz duyarız en büyük zevkini ruhumuzun

Görünce bir köylünün kıvrılmayan belini...

Başka sanat bilmeyiz karşımızda dururken

Yazılmamış bir destan gibi Anadolu'muz

Arkadaş, biz bu yolda türküler tuttururken

Sana uğurlar olsun... Ayrillyor yolumuz.

Faruk Nafiz (Hayat, S.5, 30 Aralık 1926, s.8)

Şiirin söyleyişinde, karşıya alınan bir kitle veya anlayışın varlığı henüz ilk dörtlükten sezilmektedir. Bundan sonraki dörtlükler ise bu anlayışla şiirdeki söylemin içinden geldiği anlayışın karşılaştırmasını yapmaktadır. Eleştirinin temel dayanağı, sanat için sanat gayesi taşıyan anlayışın Anadolu coğrafyasındaki temel kaynaklara duyduğu ilgisizliktir. Divan şiiri geleneğinden başlayıp, sade dille saf şiiri sürdüren şairlere kadar genişletilebilecek bu yelpaze, toplumdan kopuk olan sanatın ve sanatçının işlevsizliğini, işlevi olmayan sanatın da değersizleşeceğini vurgulamaktadır. Görüldüğü gibi, toplumcugerçekçi şiire karşı herhangi bir doğrudan eleştiri içermeyen metinde, yolların ayrıldığı tavır sanat gayesinin öncelenişidir. Yalnız şiirin dördüncü dörtlüğünde, "orkestra seslerinden ürpermesi” ile işaret edilen şairin Nâzım Hikmet olduğu sezilir.

Faruk Nafiz’in örneklenen bir önceki şiirinde, şïr perisi imajı üzerinden işaret ettiği aynı düşünce, bu metinde daha olgunlaştırılmış bir şekilde okuyucu karşısına çıkar. Faruk Nafiz’in bu olgunlaşma esnasında toplumcu-gerçekçi şiire ait bir çevreden ve söylem özelliklerinden de uzaklaşmış olduğu anlaşılır. Şiirde dikkati çeken bir başka unsur daha vardır. Esasında, sanata kaynak olarak gösterilen Anadolu'yu şair öznenin de bütün nitelikleri ile tanıdığı söylenemez. Anadolu dışarıdan, bir problem olarak kuşatılan bir obje olacaktır. Şiirde bu durum Anadolu'nun destanının henüz yazılmadığını bildiren mısralarla belirginleştirilir. Böylelikle memleketçi şiirin takip edeceği yol, daha somut biçimde ifade edilmiş olur.

\section{Sonuç}

Cumhuriyet'in ilanından hemen önce ve sonrasında edebiyatta beliren paradigmaların, istikametlerine kesin sinırlarla yerleşmeden önce birbirleriyle kesişen nitelikleri haiz olduğu söylenebilir. Bu bağlamda farklı düşünce yapılarına sahip şairlerin de bu değişkenlikten etkilendikleri ve şiirlerinde değişik ideolojik söylemlerin içinde varlık gösterdikleri gözlemlenebilir. Bu durumda şairlerin kişisel gelişim süreçleri ve zaman içinde değişen hayata bakışları da etkilidir. Cumhuriyet dönemi Türk şiirinin öncü şairlerinden sayılabilecek Faruk Nafiz Çamlıbel’in de sanat ve güzelliği önceleyerek başlayan şiir serüveni geçen ylllar içinde değişiklik göstermiştir. Büyük ölçüde millî edebiyat zevk ve anlayışından Cumhuriyetin kurulmasıyla memleketçi anlayışa evrilen şiir anlayışı içinde kalan Faruk Nafizin, 
The Influence of the Soviet Thought on the Aydinlk Magazine (1921) A prototype of Faruk Nafiz's Poem Sanat / D. Apaydin (p. 12-20)

özellikle 1920'li yılların ilk yarısında toplumcu-gerçekçi şiir anlayışından da bir ölçüde etkilendiği düşünülmektedir. Bu etkilenmenin kaynă̆ı olarak gösterilen Anadolu'ya adlı şiirin, Sovyet ideolojisinin ve temsil ettiği değerlerin Anadolu coğrafyasında tanıtılmasını ve yayılmasını amaçlayan Aydınlık mecmuasında yayımlanmış olması bu düşünceyi kuvvetlendirmektedir. Ayrıca Cumhuriyetin kuruluşundan sonra eski başkent İstanbul'un karşısında yeni başkent Ankara'da çımaya başlayan ve barındırdığı bütün göstergelerle hâkim Cumhuriyet ideolojisinin temsilcisi / taşıyıcısı konumunda olan Hayat mecmuasında Faruk Nafiz’in en ünlü şiirlerinden biri yayımlanır. Anadolu'ya adlı metnin yayımlanmasından yaklaşık iki yıl sonra yayımlanan Sanat adlı şiir, memleketçi şiirin poetikası konumundadır. Aydınlık'ta yayımlanan Anadolu'ya adlı şiirin olgunlaştırılmış bir varyasyonu olarak değerlendirilebilecek Sanat şiiri, yalnızca sanatı önceleyen şiir anlayışını hedef alır. Her iki metin bu bağlamda benzerlik göstermekle hem şairin etkilendiği farklı paradigmaları işaret etmekte hem de değişen söylemin içinde şairin öncelediği değerin Anadolu coğrafyası olduğunu sezdirmektedir.

\section{Kaynakça}

Ahmet (1924). "Şarka Çevir Yüzünü [Şiir]", Aydınlık, S.21, s.545.

Çıla, Selçuk (2010). Türk Edebiyatında Manzum Poetikalar 1860 - 196o, Akçă̆ Yay., Ankara.

Faruk Nafiz [Çamlıbel] (1924). “Anadolu’ya [Şiir]”, Aydınlık, S.26, s.671.

Faruk Nafiz [Çamlıbel] (1926). "Sanat [Şiir]”, Hayat, S.5, s.8.

Karakılıç, Selçuk (2018). "Yeter Söz Savunmanın!, Sürgün İntihal ve İntihar - Edebiyatımızın Siyasetle Imtihanı, Ötüken Neşriyat, İstanbul, s.105-122.

Nazım Hikmet [Ran] (2011). Bütün Şiirleri, Yapı Kredi Yay., İstanbul.

Sağlam, Nuri (2006). "Faruk Nafiz Çamlıbel'in Memleketçi Şiirlerinde Anadolu ve Anadolu İnsanı", Journal of Turkish Studies, Volume: 30/III, Harvard University, s. 71-88.

Şarkh (1924). “Genç Leninistler Türküsü [Şiir]” Aydınlık, S.24, s.632.

Timurtaş, Faruk K. (1974). "Han Duvarları”, Faruk Nafiz Çamlıbel - Bütün Cepheleriyle Hayatı Hatıraları Şïrleri (Haz. Hilmi Yücebaş), Yaylacık Matbaası, İstanbul, s.190-193.

Yaşar Nezihe [Bükülmez] (1923). “Kızıl Güller [Şiir]”, Aydınlık, S.16, s.415. 